\title{
Research on Smart Growth of Sustainable Cities Based on Information Entropy and Super-Efficiency DEA Model
}

\author{
Ximing Lv ${ }^{1,2}$, Shunkai Zhang ${ }^{3}$, Ang $\mathrm{Li}^{3}$, Jianbao $\mathrm{Li}^{3}$ \\ ${ }^{1}$ School of Mathematical Sciences, Inner Mongolia University, Hohhot, China \\ ${ }^{2}$ School of Statistics and Mathematics, Inner Mongolia University of Finance and Economics, Hohhot, China \\ ${ }^{3}$ School of Finance, Inner Mongolia University of Finance and Economics, Hohhot, China \\ Email: lvximing@vip.163.com
}

How to cite this paper: Lv, X.M., Zhang, S.K., Li, A. and Li, J.B. (2017) Research on Smart Growth of Sustainable Cities Based on Information Entropy and Super-Efficiency DEA Model. Journal of Applied Mathematics and Physics, 5, 1198-1214. https://doi.org/10.4236/jamp.2017.55103

Received: May 8, 2017

Accepted: May 28, 2017

Published: May 31, 2017

Copyright $\odot 2017$ by authors and Scientific Research Publishing Inc. This work is licensed under the Creative Commons Attribution International License (CC BY 4.0).

http://creativecommons.org/licenses/by/4.0/

\begin{abstract}
Since the "smart growth" was put forward in the late 90s, it has become an accepted design idea and concept in the field of urban design in the world, and has been deeply studied and applied. In order to better promote "smart grown", we set up an evaluation system, which consists of eleven indicators. In this paper, Oxford City and Fengzhen City are used as the objects of the study. Then smart growth evaluation model is established. The weight of the index is calculated by the entropy method. We use the model to evaluate the development plans of the two cities, from which to calculate the contribution of the indicators on the level of smart growth. Finally, we use the super-efficient data envelopment analysis model (DEA) to rank the importance of the indicators to the smart growth. The results show that the level of smart growth in Oxford is higher than that in Fengzhen. And "Multifunctional Building Density in Central City", "The Density of Public Area in Central City" two indicators account for more than $36 \%$ weight. The contribution of the two indicators is also located in the top two indicators. Two cities focus on the direction of smart growth is also different. In summary, the differences between China and Western countries in urban planning are mainly focused on housing and public resources.
\end{abstract}

\section{Keywords}

Smart Growth, Entropy Method, Super-Efficiency Evaluation

\section{Introduction}

Information is a very abstract concept. People often say a lot of information, or less information, but it can be quantified as its specific value. Until 1948, Claude Elwood Shannon put forward the concept of "information entropy" to solve the 
problem of quantitative measurement of information [1]. The word entropy is Claude E. Shannon borrowed from thermodynamics. The thermal entropy in thermodynamics is the physical quantity that represents the degree of molecular disorder. The concept of agricultural information entropy is used to describe the uncertainty of the source. He used mathematical language to clarify the relationship between probability and information redundancy [2].

Information entropy, is a mathematically quite abstract concept, where the information entropy may wish to understand the probability of a particular information. And information entropy and thermodynamic entropy are closely related [3]. According to Charles H. Bennett's reinterpretation of Maxwell's Demon, the destruction of information is an irreversible process, so the destruction of information is consistent with the second law of thermodynamics [4]. And generate information, it is for the system to introduce negative (thermodynamic) entropy process [5]. So the symbol of information entropy and thermodynamic entropy should be the opposite. In general, when a probability of information appears higher, it indicates that it is propagated more widely, or that the degree of reference is higher [6].

We can think that information entropy can represent the value of information from the perspective of information dissemination. In this way, we have a measure of the value of in-formation standards, can make more questions about the problem of knowledge flow.

In 2000, the American Planning Association, in conjunction with 60 public groups, formed the "Smart Growth America", which identified core elements of smart growth. However, few scholars have studied the impact of intelligent growth on urban development [7]. So we have to study the impact of intelligent growth on urban development factors (indicators) and their respective impact.

To sum up, in this paper, the use of information entropy theory can be a very good solution to our problems. The degree of influence of each factor is measured by information entropy.

In this paper, in addition to the use of information entropy model, we also use the DEA model (data envelopment analysis) to solve a problem about Which indicator is more potential.

In 1978, a well-known operational scientist A. Charnes, W. W. Cooper and E. Rhodes first proposed a method called Data Envelopment Analysis (DEA) to evaluate the relative effectiveness of departments (hence Known as DEA effective). Their first model was named CCR model. From the point of view of the production function, this model is used to study the "ideal" and "effective" method with multiple inputs, especially the "production sector" with multiple outputs. In the latter part of the content we will use the BBC model to solve the problem [8].

\section{Smart Growth Evaluation Model}

\subsection{Index System}

After analyzing the relevant literature and analyzing the problem, we determined 
the influencing factors of the theory of intelligent growth and the index system. First of all, we identified the intelligent development goals composed of three aspects through access to some references and research reports. These three aspects are economically prosperous, socially equitable and environmentally sustainable. Finally, we divided the three big indicators into 11 small indicators through analysis. The relationship between the indicators can be seen from Figure 1.

Multifunctional Building Density in Central City

This indicator refers to the density of buildings in the central area of the city

The Richness of Housing Types in Central City

This indicator refers to the types of housing in the city center area.

The Richness of Traffic Mode in Central City

This indicator refers to the types of traffic in the city center area.

Commuting Efficiency of Residents to Government

This indicator refers to the number of central city government offices.

Convenient Level of Education in Central City

This indicator refers to the number of educational institutions in the central area of the city.

Convenient Level of Medical Care in Downtown

This indicator refers to the number of medical institutions in the central city.

The "Tidal Effect" Level of the central city

This indicator refers to the number of people who work in the central city during the day and return to the suburbs in the evening.

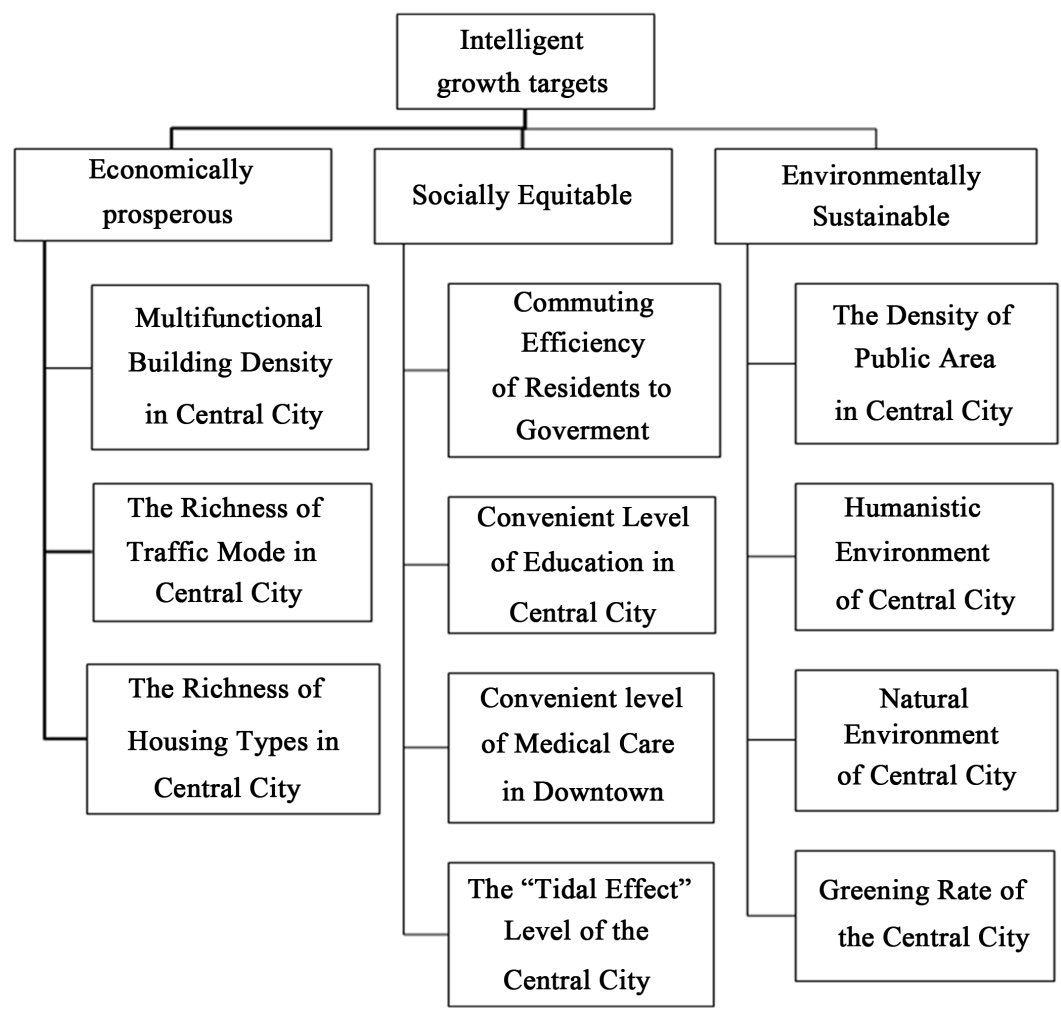

Figure 1. The index system. 
The Density of Public Area in Central City

This indicator refers to the number of public places in the central city area.

Humanistic Environment Level in Central City

This indicator refers to the number of places in the center city museum and other places.

Natural Environment of Central City

This indicator refers to the number of parks in the central city.

Greening Rate of the Central City

This indicator refers to the green area of the central city.

\subsection{Why Choosing Oxford and Fengzhen as Examples?}

In order to better study the questions raised, we need to select two completely different cities for comparison and analysis. Different cities are located in different countries, with different cultural systems and economic prosperity. In addition, we will determine the urban population between 100000 and 500000 . Because the city between this range is small and medium-sized city. The development of small and medium cities there is room for growth. Finally, the study was identified as Oxford (UK) and Fengzhen (China).

\subsection{City Introduction}

\subsubsection{Oxford}

The city's total population of 157,997 , the urban area of 45.59 square kilometers, Oxford was established in the 9th century, 1100 years ago. Oxford is the cradle of British royalty and scholars. Oxford is a well-known British university city, but it also has a lot of commercial enterprises, especially a lot of high-tech enterprises. Oxford is located at $51^{\circ} 45^{\prime} \mathrm{N}, 1^{\circ} 15^{\prime} \mathrm{W}$. As a historic city, it has maintained a compact and high-density form, and is widely regarded as an ideal environment for living and working. Oxford map information can be seen from Figure 2.

According to the latest statistics, Oxford's comprehensive ranking in the British cities in the middle position. Oxford's ranking in British cities can be seen intuitively from Figure 3.

\subsubsection{Fengzhen}

Fengzhen has abundant natural resources. In recent years, Fengzhen City has also vigorously developed the industry and commerce. Fengzhen is located at $40^{\circ} 43^{\prime} \mathrm{N}, 113^{\circ} 15^{\prime} \mathrm{E}$. Fengzhen as a heavy industrial city, its urban development is expansionary, like many Chinese cities.

According to the latest data, Fengzhen City's comprehensive ranking in the middle position relative to other cities in mainland China. Fengzhen map information can be seen from Figure 4.

\subsection{Hypothetical Premise}

- In this paper, the central of city area is provided by the two municipalities. We will use the red coil out of the central city specific scope in the map. 


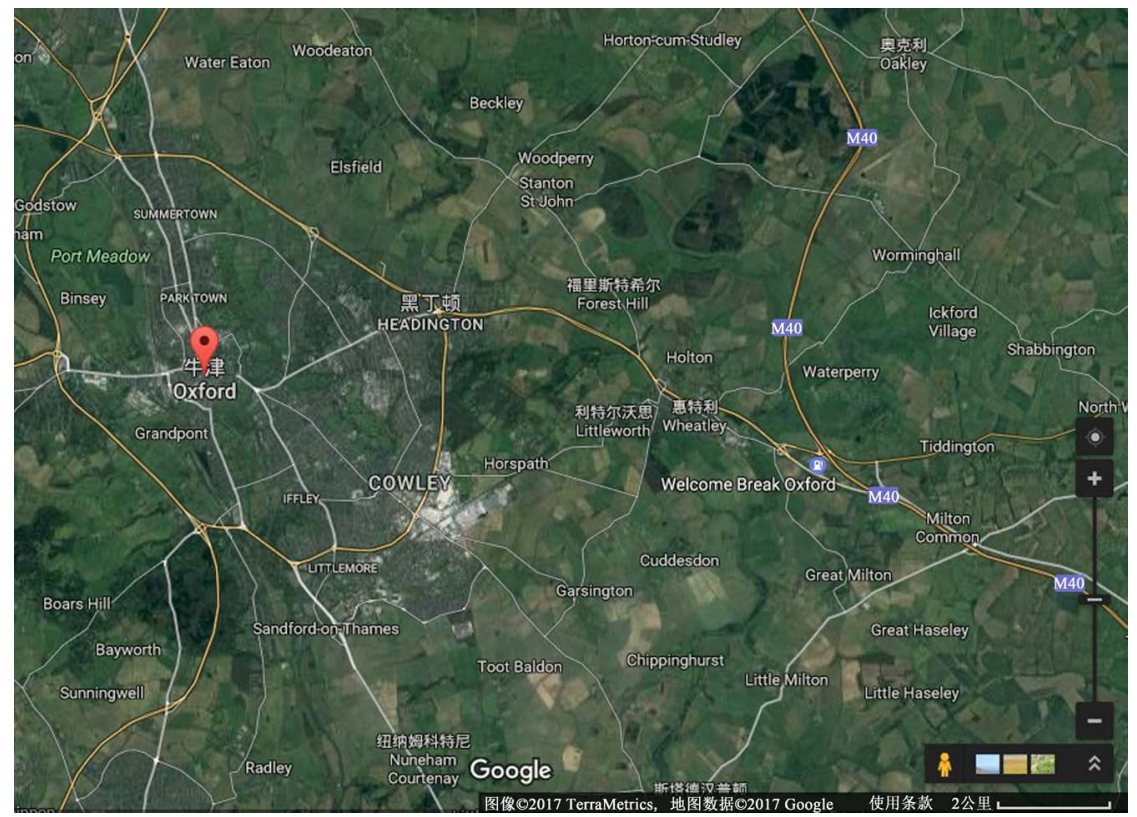

Figure 2. Map of Oxford.

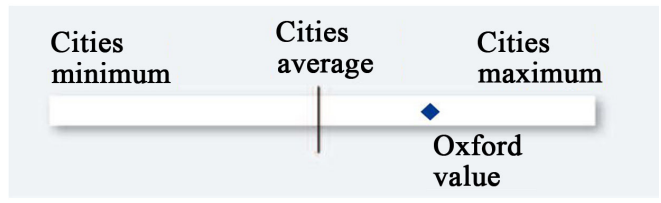

Figure 3. The middle position.

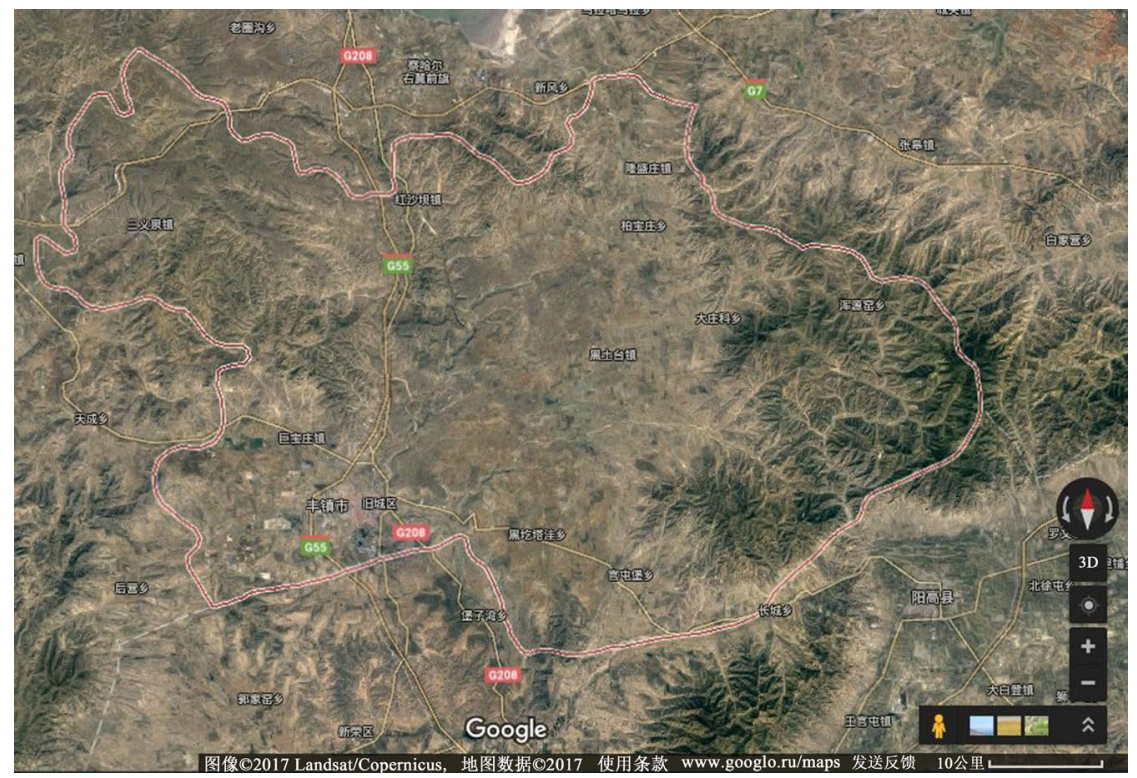

Figure 4. Map of Fengzhen.

- All the data used in this article are collected on the network. Data is real and effective.

- In this paper, the unit of area is square kilometers.

- The types of vehicles described in this paper are: public bicycles, buses, trolley 
buses, trams, underground railways, fast trams, taxis, walking.

- The types of houses described in this article are: apartment, studio, secondary unit, loft, condominium, basement, duplex, semi-detached, terraced house, townhouse.

\subsection{The Development Strategy of the Two Cities}

\subsubsection{Development Strategy of Oxford City}

- The following is the development strategy of Oxford:

- The high quality of the built and natural environment;

- The diversity of the economic base;

- The compact nature of Oxford, and its accessibility;

- The reputation of the health care and education institutions;

- Provide decent accommodation for all, taking into account the changing household profile and housing need;

- Control of parking in the city centre;

- Bus priority measures;

- Facilities for pedestrians and cyclists; and park and ride;

\subsubsection{Development Strategy of Fengzhen City}

- The following is Fengzhen City's development strategy:

- By 2017, we want to build five agricultural trade complex, a comprehensive commercial and trade area, 13 shopping complex in the central city;

- By 2017, we want to remove some of the old houses, and want to build 500 sets of new apartments in the place after the demolition;

- Before 2017, we will have to transform and expand the small hospitals in the cities to form large-scale medical institutions. In addition, we have to build two urban medical centers;

- In 2017, we have to build a high school, a junior high school, a primary school.

\subsection{Are These Policies Consistent with Our Principles?}

We will use our evaluation system to measure the development strategies of the two cities.

First, we will have a few important logical deductions that are important for understanding the following.

It's an abstraction to get the city's plan in line with the "smart grown" principle. Therefore, the first thing we want to do is to quantify the behavior of compliance.

To solve this problem, we have borrowed from evolutionary behavior in biology.

As we know, the appearance of species more and more like the current appearance, through continuous evolution. Like the appearance, the other characteristics of the species in the evolution of the process is the same performance. Here we specify that there is only one evolutionary direction-although this is somewhat inconsistent with the biological theory. 
We assume that A is the "smart grown principle", is the ultimate form of urban development principles. The current principle of urban development is $B$, which is the primary form of the final form $A$. Evolution from $B$ to $A$ has only one direction. $B_{2}$ is the evolution of $B_{1}$, and so on. The number of evolutionary behaviors between $A$ and $B$ is unknown. But we know that as long as the evolution of $B$, it is close to the final form $A$.

If here $A, B, B_{2}$ can be quantified, then $\partial\left(\partial=\frac{B_{2}-B}{B}\right)$ is an evolution rate,

Ibetween $B_{2}$ and $B$. The greater the number of this evolution rate, the closer the $B_{2}$ is to $A$.

We define $\partial$ as the evolutionary rate of urban development principles. The logical diagram of the above statement is Figure 5.

To calculate the value of $\partial$, you must know $B_{2}$ and $B$.

We use the following method to solve this problem:

We let the value of $B$ be infinitely close to the value 0 , so that the result number of $\partial$ is approximately equal to the number of the current $B_{2}$, although their meaning is not the same.

In this way, we make $\partial=B_{2}$ on the numbers. So, we only need to find a way to calculate $B_{2}$, we can find $\partial$. This approach has greatly reduced our work.

Now, we begin to consider how to calculate $B_{2}$. Because $B_{2}$ is a reflection of current development principles, we make the following assumptions:

It can be quantized as a real number.

It consists of the quantitative values of the evaluation indicators in our evaluation system.

So the next we will encounter the following problems:

- How to quantify each evaluation index?

- The relationship between $B_{2}$ and the quantitative value of the evaluation index.

\subsection{Index Analysis}

Simple indicators can't be quantified. We need to extract the indicators that can be quantified.

- Multifunctional Building Density in Central City

We use the multi-purpose building area divided by the center city area, to represent the "Mix land uses" principle in the implementation of the central city.

- The Richness of Housing Types in Central City

We use the type of housing owned by the central urban area divided by the total urban housing type to represent this meaning.

- Commuting efficiency of residents to government agencies

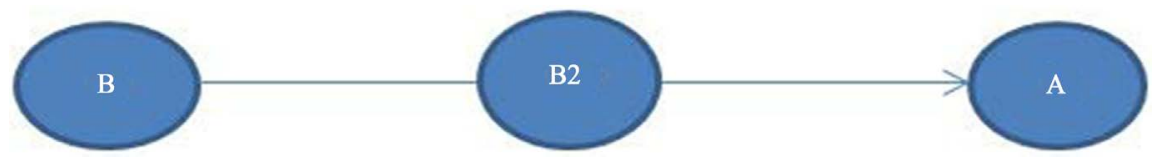

Figure 5. Evolutionary presentation. 
We use the number of government agencies in the central urban area divided by the central city area to represent this meaning.

- The Density of Public Area in Central City

We use the central city square divided by the total area of the central city to express its degree.

- Humanistic Environment Level in Central City

We use the number of museums in the downtown area divided by the total area of the city to represent the human environment of the central city.

- Natural Environment Level of Central City

We use the number of natural parks in the central urban area divided by the total area of the central urban area to represent the natural environment of the central urban area.

- Greening rate of the central city

We use the central urban greening rate to indicate its degree.

- The Richness of Traffic Mode in Central City

We use the means of transportation that can be used in the central area divided by the type of transportation to express the richness of the means of transportation in the central urban area.

- Convenient Level of Education in Central City

We use the number of education centers in the central city divided by the center city area to represent the central city residents education convenient level.

- Convenient level of medical care in downtown area

We use the number of medical institutions divided by the center city area to represent the central city residents convenient medical standards.

- The "Tidal Effect" Level of the Central City

We use the number of employees living outside the central urban area divided by the total number of employees working in the central urban area to express the tidal effect ratio.

According to the above analysis we extracted two cities for 20 years of relevant data.

\subsection{Specific Model}

\subsubsection{Looking for Mathematical Relations}

We have established smart growth evaluation model to calculate the level of smart growth of the city.

$$
U=\sum_{i=1}^{n} w_{i} f_{i}
$$

The contents of Table 1 are the Symbolic explanation in Equation (1).

Table 1. Symbolic explanation.

\begin{tabular}{cc}
\hline symbol & Symbolic explanation \\
\hline$U$ & The value of "Intelligent growth targets" \\
$w_{i}$ & The weight of each index \\
$f_{i}$ & Indexes about smart growth \\
\hline
\end{tabular}


Then, we will give each index system weight, and finally calculate the two cities "smart growth" level and look for the weight of each indicator system.

\subsubsection{Data Processing}

The data needs to be processed before the calculation is performed using the entropy method. There are primary and secondary indicators in this paper. The calculation steps are as follows.

- The primary index $k$ includes $\mathrm{m}$ secondary index information and $\mathrm{n}$ city sample information. The data matrix is formed:

$$
D_{k}=\left[\begin{array}{cccc}
d_{11} & d_{12} & \cdots & d_{1 m} \\
d_{21} & d_{22} & \cdots & d_{2 m} \\
\vdots & \vdots & \ddots & \vdots \\
d_{n 1} & d_{n 2} & \cdots & d_{n m}
\end{array}\right]
$$

$M$ is the number of secondary indicators included in the k-th level, and $n$ is the number of selected cities.

- The data matrix is averaged, because the selected secondary index in the data matrix is different from the order of magnitude and dimension. To eliminate its impact, the data matrix is required to be averaged [9].

The original data $(n \times m)$, set the secondary index means $Z_{i j}$, data is expressed as:

$$
Z_{i j}=\frac{D_{i j}}{D_{j}}
$$

The mean data matrix is:

$$
Z_{k}=\left[\begin{array}{cccc}
Z_{11} & Z_{12} & \cdots & Z_{1 m} \\
Z_{21} & Z_{22} & \cdots & Z_{2 m} \\
\vdots & \vdots & \ddots & \vdots \\
Z_{n 1} & Z_{n 2} & \cdots & Z_{n m}
\end{array}\right]
$$

The original data mainly includes two parts of the information: (1) changes in the indicators of the differences in information; (2) indicators of the impact of each other related information. It is represented by the correlation matrix of the data. Data averaging can not only eliminate the influence of orders of magnitude and schedules [10].

And it does not change the correlation between the indicators of the original data. The mean data after the package can retain all the original information, so this paper uses the mean way to deal with the original data.

After the data processing is completed, we calculate the information entropy.

\subsubsection{The Derivation of Entropy Method}

From the microscopic point of view, the entropy of the system can be derived from the statistics of molecular arrangement [11]. Assume that there are two substances in the system (binary system), $A$ substance has $n_{1}$ molecules, $B$ substance has $n_{2}$ molecules, The entropy of the system can be calculated by the Boltzmann formula: 


$$
E=K \ln \Omega
$$

$\Omega$ is the arrangement of two molecules in the system. According to the formula: $\Omega=\frac{\left(n_{1}+n_{2}\right) !}{n_{1} ! n_{2} !}$, then:

$$
E=-K\left[n_{1} \ln \frac{n_{1}}{n_{1}+n_{2}}+n_{2} \ln \frac{n_{2}}{n_{1}+n_{2}}\right]
$$

$E$ is the total entropy of the system $\left(n_{1}+n_{2}\right)$, Divided by the total number of molecules, so as to obtain the system unit entropy:

$$
e=\frac{E}{n_{1}+n_{2}}=-K\left[\frac{n_{1}}{n_{1}+n_{2}} \ln \frac{n_{1}}{n_{1}+n_{2}}+\frac{n_{2}}{n_{1}+n_{2}} \ln \frac{n_{2}}{n_{1}+n_{2}}\right]
$$

$y_{1}=\frac{n_{1}}{n_{1}+n_{2}}, \quad y_{2}=\frac{n_{2}}{n_{1}+n_{2}}$ respectively indicate system $\mathrm{A}$ and $\mathrm{B}$ substance occupancy rate. The unit entropy of the system is:

$$
e=-K\left(y_{1} \ln y_{1}+y_{2} \ln y_{2}\right)
$$

Extended to a multiple $(n)$ system, the unit entropy function is:

$$
e=-K \sum_{i=1}^{n} y_{i} \ln y_{i}
$$

As the size of the indicators in this issue, the magnitude and direction of the indicators are different. So we need to standardize the data processing [12].

In the information entropy function formula, the constant $K$ and the system number of samples $m$ associated. For a system with completely disordered information, the degree of order is zero, the maximum entropy is $e=1$, and when samples are in a completely disordered state, $y_{i}=\frac{1}{m}$, at this time,

$$
e=-K \sum_{i=1}^{n} \frac{1}{m} \ln \frac{1}{m}=K \sum_{i=1}^{n} \frac{1}{m} \ln \frac{1}{m}=K \ln m=1
$$

Inferred: $K=\frac{1}{\ln m}(0 \leq e \leq 1)$. The information entropy $e_{i}$ can be used to measure the utility value of the index information. When the information is unordered, $e_{i}=1$, then the information of $e_{j}$ has zero utility value to the comprehensive evaluation. Therefore, the information utility value of an indicator depends on the difference between the information entropy of the index $e_{i}$ and $d_{i}$ is 1 .

$$
d_{i}=1-e_{i}
$$

The weight of each index is estimated by information entropy. Its essence is calculated by using the value coefficient of the index. The higher the value coefficient is, the greater the importance of the index is. Finally, we can get the weight of the i-th index:

$$
w_{i}=\frac{d_{i}}{\sum_{i=1}^{n} d_{i}}
$$


After the data collection and formula calculation, we get the value of ei which can be given by Table 2 and indicator weight which can be given by Table 3 .

\subsubsection{Quantitative Evaluation}

We used the model to evaluate the development plans of the two cities over the next five years. Through analysis we can get the contribution of indicators to the level of intelligent development. The results can be seen from Table 4 .

\subsubsection{Comparative Analysis}

According to the results of Table 4, we conducted a comparative analysis. Oxford's development program focuses on protecting the ecological environment and increasing the function of urban architecture. However, Oxford's plans are

Table 2. The value of ei.

\begin{tabular}{cc}
\hline The name of the metric & The value of ei \\
\hline Multifunctional Building Density in Central City & 0.0518 \\
The Richness of Housing Types in Central City & 0.5 \\
Commuting efficiency of residents to government agencies & 0.07017544 \\
The Density of Public Area in Central City & 0.013 \\
Humanistic Environment Level in Central City & 0.01754386 \\
Natural Environment Level of Central City & 0.0118 \\
Greening rate of the central city & 0.5 \\
The Richness of Traffic Mode in Central City & 0.2022 \\
Convenient Level of Education in Central City & 0.175438596 \\
Convenient level of medical care in downtown area & 0.175438596 \\
The “Tidal Effect" Level of the Central City & 0.67 \\
\hline
\end{tabular}

Table 3. Indicator weight.

\begin{tabular}{cc}
\hline The name of the metric & Indicator Weight \\
\hline Multifunctional Building Density in Central City & 0.154199 \\
The Richness of Housing Types in Central City & 0.070915 \\
Commuting efficiency of residents to government agencies & 0.096182 \\
The Density of Public Area in Central City & 0.214487 \\
Humanistic Environment Level in Central City & 0.122716 \\
Natural Environment Level of Central City & 0.117569 \\
Greening rate of the central city & 0.006925 \\
The Richness of Traffic Mode in Central City & 0.096939 \\
Convenient Level of Education in Central City & 0.052809 \\
Convenient level of medical care in downtown area & 0.041739 \\
The “Tidal Effect" Level of the Central City & 0.025519 \\
\hline
\end{tabular}


Table 4. The value of index contribution.

\begin{tabular}{ccc}
\hline The name of the metric & Fengzhen & Oxford \\
\hline Multifunctional Building Density in Central City & 0.1167 & 0.0842 \\
The Richness of Housing Types in Central City & 0.1 & 0.0467 \\
Commuting efficiency of residents to government agencies & 0.0351 & 0.0256 \\
The Density of Public Area in Central City & 0.003 & 0.0016 \\
Humanistic Environment Level in Central City & 0.035 & 0.0578 \\
Natural Environment Level of Central City & 0.0526 & 0.0231 \\
Greening rate of the central city & 0.16 & 0.24 \\
The Richness of Traffic Mode in Central City & 0.00 & 0.0125 \\
Convenient Level of Education in Central City & 0.0526 & 0.0326 \\
Convenient level of medical care in downtown area & 0.0351 & 0.014 \\
The "Tidal Effect" Level of the Central City & 0.04 & 0.06 \\
The evolutionary rate of urban development principles & 0.0460 & 0.0356 \\
\hline
\end{tabular}

less visible in the economy. While the development plan of Fengzhen City focuses on economic and social equity and reflects less on environmental sustainability. However, the two cities are part of the development plan of intelligent growth reflected, although some do not reflect too much. Overall, between the two cities, Oxford's development plan focuses more on smart growth. The specific level of success needs to be measured by our evaluation model.

\section{Which Indicator Is More Potential}

Because studying which Indicators have more potential is necessary. We do the following research. We use the super-efficiency model to calculate the potential value of Indicators.

\subsection{Data Envelopment Analysis (DEA)-BCC Model}

Data Envelopment Analysis (DEA) method and its extended form are better objectivity than other methods [13]. It has a clear advantage in measuring the relative efficiency of multi-input, multi-output decision-making units. So this method is widely used by scholars. From the model form, the traditional DEA model includes CCR model and BCC model [14]. The Data Envelopment Analysis (DEA)-CCR model is a DEA model of basing on the scale pay invariant hypothesis and Data Envelopment Analysis (DEA) -BCC model is a DEA model of basing on the scale payable hypothesis. Under normal circumstances, the latter is more in line with the actual situation. Suppose there are $\mathrm{n}$ decision units (DMU), each decision unit has $\mathrm{m}$ kinds of input and s output. $x_{k}=\left(x_{1 k}, x_{2 k}, \cdots, x_{m k}\right)^{\mathrm{T}}$, $y_{k}=\left(y_{1 k}, y_{2 k}, \cdots, y_{m k}\right)^{\mathrm{T}} . x_{i k}>0$ is the $\mathrm{i}$-th output variable for the $\mathrm{k}$-th decision unit [15]. $y_{j k}>0$ is the k-th output variable of the j-th unit. $x_{0}=x_{k 0}$ and $y_{0}=y_{k 0}$ are the inputs and outputs of the decision unit DMU, respectively. The BCC model to determine its validity is: 


$$
\left\{\begin{array}{l}
\min \theta_{0} \\
\text { s.t. } \theta_{0} x_{i 0} \geq \sum_{k=1}^{n} \lambda_{k} x_{i k}, i=1,2, \cdots, m \\
y_{j 0} \leq \sum_{k=1}^{n} \lambda_{k} y_{j k}, j=1,2, \cdots, s \\
\sum_{k=1}^{n} \lambda_{k}=1, \lambda_{k} \geq 0, k=1,2, \cdots, n
\end{array}\right.
$$

The BCC model has two flaws. (1) The efficiency of the decision unit can't be further evaluated when multiple units are active at the same time. (2) The radial nature of the model leads to the inability to consider the problem of slackness of inputs and outputs.

Andersen and other scholars in 1993 proposed an improved model of BCC model which is super-efficiency DEA model [16]. It overcomes the DEA model can't make further evaluation and comparison of multiple decision-making unit defects and make effective decision making units can compare and sorting. While making an efficiency evaluation of a decision making unit, we exclude its first. In the assessment, it is invalid in terms of decision making units. Its production frontier is changeless. So its final efficiency value is measured as measured by the traditional DEA model. However, in terms of the effective decision-making unit, the proportion of the input is increased in proportion to the increase in the efficiency value, and the proportion of the input is recorded as the super-efficiency evaluation value [17]. Because of its production frontier backwards, therefore, to determine the efficiency value is greater than traditional DEA model has been applied to the determination of value of efficiency. As shown in Figure 1, when calculating the efficiency value of the unit $B$, to be excluded, DMU to participate in the collection is ACDE became line said the point $B$ still can increase the size of the inventory. Point B super-efficiency value is $\frac{B^{\prime}}{B}>1$. Further, A, C, D point of efficiency evaluation in accordance with the same logic can be calculated, and their value is greater than 1 [18]. The relationship between the input and output units in the model can be seen in Figure 6 .

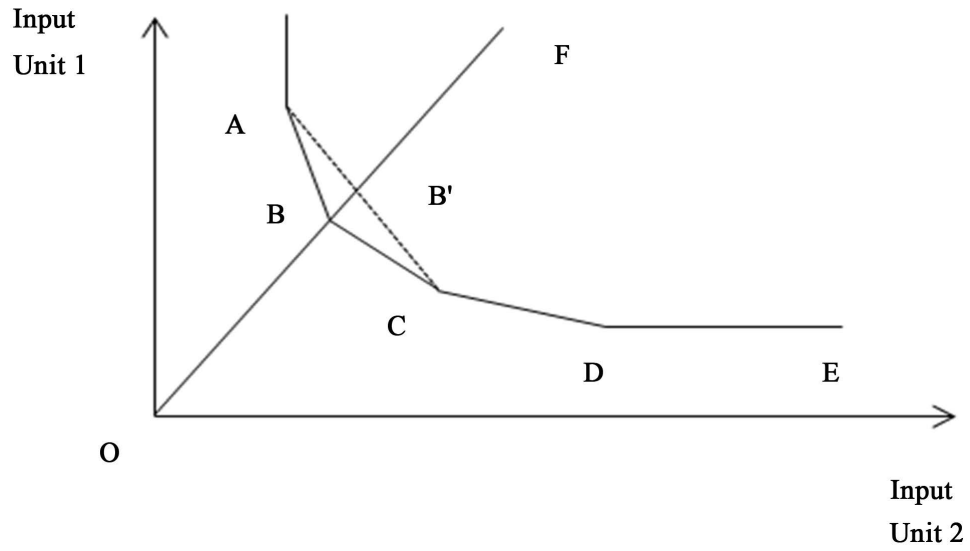

Figure 6. Constant returns to scale of super-efficiency DEA model. 


\subsection{The Mathematical Form of Super-Efficiency Model}

The basic form of non-radial super-efficiency BCC model is:

$$
\left\{\begin{array}{l}
\min \rho_{1}=\theta_{0}^{s} / \phi_{0}^{s} \\
\text { s.t. } \theta_{0}^{s} x_{i 0} \geq \sum_{n} \lambda_{k} x_{i k}, i=1,2, \cdots, m \\
\theta_{0}^{s} y_{j 0} \geq \sum_{n} \lambda_{k} y_{j k}, j=1,2, \cdots, s \\
\sum_{n} \lambda_{k}=1, \lambda_{k} \geq 0, k=1,2, \cdots, n, k \neq 0 \\
0<\theta_{0}^{s} \leq 1, \phi_{0}^{s} \geq 1
\end{array}\right.
$$

Equation (14) belongs to the input-oriented model, indicating that the decision unit DMU only with the input level $\theta_{0}^{s}$ can get the output $\phi_{0}^{s}$.

The output-oriented non-radial over-efficiency BCC model is:

$$
\left\{\begin{array}{l}
\min \rho_{1}=\theta_{0}^{s} / \phi_{0}^{s} \\
\text { s.t. } \theta_{0}^{s} x_{i 0} \geq \sum_{n} \lambda_{k} x_{i k}, i=1,2, \cdots, m \\
\theta_{0}^{s} y_{j 0} \geq \sum_{n} \lambda_{k} y_{j k}, j=1,2, \cdots, s \\
\sum_{n} \lambda_{k}=1, \lambda_{k} \geq 0, k=1,2, \cdots, n, k \neq 0 \\
0<\phi_{0}^{s} \leq 1, \theta_{0}^{s} \geq 1
\end{array}\right.
$$

Combining Equation (14) and Equation (15) can achieve the ranking of decision making units. The steps are:

- The efficiency value $\rho_{1}$ is calculated for the decision unit DMU according to Equation (14). If $\rho_{1} \leq 1$, then $\rho_{1}$ is the efficiency of the decision-making unit, and go to the third step, otherwise go to the second step.

- Calculate the efficiency value $\rho_{2}$ for the decision unit DMU according to Equation (15). Then $\rho_{2}$ is the efficiency of the decision unit.

- Repeat the above steps for the next decision unit until the decision efficiency values for all cells are obtained.

The model takes into account some practical factors such as the change in the proportion of factors input, the preferences of decision makers, and so on. At the same time, the measured technical efficiency level can be greater than 1 . This solves the problem of efficiency comparison of multiple effective decision units.

\subsection{Result}

Then we used the DEA analysis software (MAXDEA) to calculate the potential value of Indicators. The results can be seen from Table 5.

\subsection{Result Analysis}

From the result of Table 5, we can find the following information. Fengzhen city and Oxford city development type is different. Fengzhen is a resource-driven city, while Oxford is a business-led city. So the two urban development plans are not the same. No mention or mention of fewer indicators has had a significant impact on urban development. For example: Fengzhen City development plan 
Table 5. Indicator importance ranking.

\begin{tabular}{ccccc}
\hline The name of the metric & FengZhen & Rank & Oxford & Rank \\
\hline Multifunctional Building Density in Central City & 0.663 & 7 & 1.509 & 5 \\
The Richness of Housing Types in Central City & 0.554 & 9 & 1.805 & 3 \\
Commuting efficiency of residents to government agencies & 1.396 & 4 & 0.717 & 8 \\
The Density of Public Area in Central City & 1.731 & 3 & 0.578 & 9 \\
Humanistic Environment Level in Central City & 4.279 & 1 & 0.234 & 11 \\
Natural Environment Level of Central City & 3.558 & 2 & 0.281 & 10 \\
Greening rate of the central city & 0.632 & 8 & 1.583 & 4 \\
The Richness of Traffic Mode in Central City & 0.474 & 10 & 2.111 & 2 \\
Convenient Level of Education in Central City & 1.07 & 6 & 0.935 & 6 \\
Convenient level of medical care in downtown area & 1.117 & 5 & 0.893 & 7 \\
The “Tidal Effect" Level of the Central City & 0.237 & 11 & 4.321 & 1 \\
\hline
\end{tabular}

pay more attention to economic development. So the plan that involves environment is less. The potential for environmental sustainability plans is high. While Oxford focuses on environmentally sustainable programs, the potential for environmental sustainability programs is low. The plan has little impact on the overall goal. Similarly, Fengzhen City and Oxford City have other local characteristics in other indicators. Therefore, the potential of our planned programs will vary from one city to another. Overall, Oxford's sustainable development level is higher than Fengzhen. This is also due to Oxford's early attention to the issue of sustainable development. Which led to the development of Oxford is better than Fengzhen. However, if Fengzhen City can focus on sustainable development in the development plan, we believe that Fengzhen City can also develop better and better. The above discussion also illustrates the advantages of smart growth.

\section{Conclusion}

Smart growth is the future trend of urban development. From the above study we can also find the advantage of smart growth. Smart growth enables sustainable urban development. Fengzhen City and Oxford City in the development of the two cities have their own characteristics. But there is a certain distance from the development of two cities to the standard of smart growth. Part of the plans in two cities is in line with the intelligent development, but a large part of the plans have problems. Smart growth is not yet very high penetration. However, with the development of the city, intelligent growth embodies the peopleoriented and sustainable development of the idea will show the advantage. The index system established in this paper can also be used as a reference system for evaluating the degree of urban intelligence development. We can use the index system to evaluate the development of the city and we can also modify and innovate some excellent plan according to the evaluation results. We did not study 
the impact of population growth on intellectual growth during the course of the study. We hope to further explore these factors in the next study.

\section{References}

[1] Shannon, C.E. (1949) Communication Theory of Secrecy Systems. Bell System Technical Journal, 28, 656-715. http://sci-hub.cc/10.1002/j.1538-7305.1949.tb00928.x https://doi.org/10.1002/j.1538-7305.1949.tb00928.x

[2] Shannon, C.E. (2001) A Mathematical Theory of Communication. ACM SIGMOBILE Mobile Computing and Communications Review, 5, 3-55.

http://sci-hub.cc/10.1145/584091.584093 https://doi.org/10.1145/584091.584093

[3] Downs, A. (2005) Smart Growth: Why We Discuss It More than We Do It. Journal of the American Planning Association, 71, 367-378. https://doi.org/10.1080/01944360508976707

[4] Bennett, C.H. and DiVincenzo, D.P. (2000) Quantum Information and Computation. Nature, 404, 247-255. http://sci-hub.cc/10.1038/35005001 https://doi.org/10.1038/35005001

[5] Danielsen, K.A., Lang, R.E. and Fulton, W. (1999) Retracting Suburbia: Smart Growth and the Future of Housing. Housing Policy Debate, 10, 513-540. https://doi.org/10.1080/10511482.1999.9521341

[6] Daniels, T. (2001) Smart Growth: A New American Approach to Regional Planning. Planning Practice and Research, 16, 271-279. http://210.74.184.3:8080/international/case/case/1575.pdf https://doi.org/10.1080/02697450120107880

[7] Geller, A.L. (2003) Smart Growth: A Prescription for Livable Cities. American Journal of Public Health, 93, 1410-1415.

https://www.ncbi.nlm.nih.gov/pmc/articles/PMC1447984/ https://doi.org/10.2105/AJPH.93.9.1410

[8] Cooper, W.W., Seiford, L.M. and Zhu, J. (2004) Data Envelopment Analysis. In: Handbook on Data Envelopment Analysis, Springer, Berlin, 1-39. http://sci-hub.cc/10.1007/1-4020-7798-X 1 https://doi.org/10.1007/1-4020-7798-X 1

[9] Poza, E.J. (1989) Smart Growth: Critical Choices for Business Continuity and Prosperity. Jossey-Bass Incorporated Pub.

[10] Biaynicki-Birula, I. and Mycielski, J. (1975) Uncertainty Relations for Information Entropy in Wave Mechanics. Communications in Mathematical Physics, 44, 129132. http://www.cft.edu.pl/ birula/publ/Uncertainty.pdf https://doi.org/10.1007/BF01608825

[11] Liang, J. and Shi, Z. (2004) The Information Entropy, Rough Entropy and Knowledge Granulation in Rough Set Theory. International Journal of Uncertainty, Fuzziness and Knowledge-Based Systems, 12, 37-46. https://doi.org/10.1142/S0218488504002631

[12] Liang, J., Shi, Z., Li, D. and Wierman, M.J. (2006) Information Entropy, Rough Entropy and Knowledge Granulation in Incomplete Information Systems. International Journal of General Systems, 35, 641-654. https://doi.org/10.1080/03081070600687668

[13] Wei, Q. (2001) Data Envelopment Analysis. Chinese Science Bulletin, 46, 13211332. http://sci-hub.cc/10.1007/BF03183382 
https://doi.org/10.1007/BF03183382

[14] Banker, R.D., Charnes, A. and Cooper, W.W. (1984) Some Models for Estimating Technical and Scale Inefficiencies in Data Envelopment Analysis. Management Science, 30, 1078-1092. https://doi.org/10.1287/mnsc.30.9.1078

[15] Charnes, A., Cooper, W.W. and Rhodes, E. (1978) Measuring the Efficiency of Decision Making Units. European Journal of Operational Research, 2, 429-444.

[16] Roll, Y. and Hayuth, Y.E.H.U.D.A. (1993) Port Performance Comparison Applying Data Envelopment Analysis (DEA). Maritime Policy and Management, 20, 153-161. https://doi.org/10.1080/03088839300000025

[17] Andersen, P. and Niels, C.P. (1993) A Procedure for Ranking Efficient Units in Data Envelopment Analysis. Management Science, 39, 1261-1264. https://doi.org/10.1287/mnsc.39.10.1261

[18] Banker, R.D., Charnes, A., Cooper, W.W., Swarts, J. and Thomas, D.A. (1989) An Introduction to Data Envelopment Analysis with Some of Its Models and Their Uses. Research in Governmental and Nonprofit Accounting, 5, 125-163.

Submit or recommend next manuscript to SCIRP and we will provide best service for you:

Accepting pre-submission inquiries through Email, Facebook, LinkedIn, Twitter, etc. A wide selection of journals (inclusive of 9 subjects, more than 200 journals)

Providing 24-hour high-quality service

User-friendly online submission system

Fair and swift peer-review system

Efficient typesetting and proofreading procedure

Display of the result of downloads and visits, as well as the number of cited articles

Maximum dissemination of your research work

Submit your manuscript at: http://papersubmission.scirp.org/

Or contact jamp@scirp.org 